\title{
Embryonic and larval development of honeycomb grouper Epinephelus merra Bloch
}

\author{
I Jagadis, Boby Ignatius*, D Kandasami \& Md Ajmal Khan \\ Regional Centre of Central Marine Fisheries Research Institute, Marine Fisheries PO, Mandapam Camp,Tamil Nadu, India \\ Correspondence: I Jagadis, Tuticorin Research Centre of CMFRI, South Beach Road, Tuticorin, Tamil Nadu 628 001, India. \\ E-mail: ijagadis@sify.com \\ ${ }^{*}$ Present address: Central Marine Fisheries Research Institute, Kochi, India. \\ ${ }^{\dagger}$ Present address: Chennai Research Centre of Central Marine Fisheries Research Institute, 75, Santhome High Road, R. A. Puram, \\ Chennai 600 028, India.
}

\begin{abstract}
Spawning and successful rearing of larvae of honeycomb grouper Epinephelus merra Bloch 1793 upto juvenile stage was accomplished at the finfish hatchery of Mandapam Regional Centre of Central Marine Fisheries Research Institute during 2004. The fertilized eggs were free, spherical and buoyant with size ranging from 710 to $730 \mu \mathrm{m}$. Complete early embryonic development took place within $24-27 \mathrm{~h}$ and hatching occurred. The hatchlings measured $1.5 \mathrm{~mm}$. Mouth opening $(115 \mu \mathrm{m})$ appeared at $72 \mathrm{~h}$ when the larvae were $2.2 \mathrm{~mm}$ in size. Pectoral fin developed on the fifth day. Complete metamorphosis took place and by the 60th day the larvae transformed into juveniles $(45 \mathrm{~mm})$ and attained skin colouration and honeycomb pattern.
\end{abstract}

Keywords: embryonic and larval development, honeycomb grouper, E. merra

\section{Introduction}

The 'Groupers' belonging to the genus Epinephelus are commercially important marine food fishes in the Indo pacific and Carribean regions. Groupers are extensively cultivated in floating/fixed net cages and coastal ponds in Southeast Asian countries. Several species of grouper have been reared on a commercial scale mainly in Japan, Taiwan, Hong Kong, Southeast and Middle East countries.

Induced maturation, spawning and larval rearing has been reported on Epinephelus spp. (Chen, Chow,
Chao \& Lim 1977; Pinij, Tiro, Pudadera \& Potestas 1986; Salem \& James 1996) Hatchery production has increased in recent years in Japan, Taiwan and Kuwait (Tucker Jr. 1999). Efforts were made at Central Marine Fisheries Research Institute, (CMFRI) to evolve a reliable technique for the mass production of seeds of groupers. Preliminary success has been achieved at CMFRI on the brood stock development, induced spawning and part larval rearing on Epinephelus tauvina (Forskal 1775), at Kochi and on Epinephelus polyphekadion (Bleeker, 1849) at Mandapam Regional Centre (Anon, 1998-1999; 2000-2001).

The present account is the first successful attempt reported from India, on the complete embryonic and larval development of honeycomb grouper Epinephelus merra Bloch upto juvenile stage. The work was carried out under the National Agricultural Technology Projects, New Delhi.

\section{Materials and method}

\section{Spawning and development}

Brood stocks of E. merra were maintained in an indoor maturation and spawning system constructed with 5 tonnes circular FRP tanks. The spawners were maintained under a feeding protocol of $10 \%$ body weight of freshly killed sardines on alternate days. Twice weekly, squid meat at 10\% body weight of the stocked fishes was also supplemented. The brood fishes spawned naturally after a maintenance period of 7 months. Six natural spawnings occurred during August to October 2004 with durations ranging from 
2 to 4 days for each spawning. The dates of the natural spawning invariably corresponded with lunar phase.

All the spawned eggs were collected with a fine scoop net $(100 \mu \mathrm{m})$ and transferred to a known volume (100 L). The number of eggs in each spawning was determined by drawing sub-samples of $1 \mathrm{~mL}$ and counting the numbers and raising to the known volume. The viable eggs were collected from the spawning tank with a fine scoop net and carefully transferred to a basin $(30 \mathrm{~L})$ containing filtered seawater. Fertilized eggs were counted and transferred to larval rearing tanks $(100 \mathrm{~L})$ filled with filtered seawater at a density of 20-30 eggs $\mathrm{L}^{-1}$ for larval development (Duray, Estudillo \& Alpasan 1995).

The live feeds required for larval rearing were cultured as detailed. The green algae Chlorella spp. were cultured in 1.0 tonnes FRP tanks following the method detailed by Gopinathan (1982). The rotifer Brachionus sp. was cultured in 1.0 tonnes FRP tanks using green water. Adult copepods for the experiments were collected by sieving raw seawater and cultured following the batch culture method described by Stottrup and Norsker (1997). Fortnightly water samples were taken from the rearing container and the water-quality parameters were monitored following standard analytical procedures.

The early embryonic development and subsequent larval growth stages were carefully followed through by drawing samples. Photomicrographs were taken with a help of Carl Zeiss binocular microscope (Zeiss, Göttingen, Germany) fitted with Ricoh camera (Ricoh, Tokyo, Japan). Measurements of the eggs and larval stages were taken (five numbers) by using an ocular micrometer precalibrated with a $1 \mathrm{~mm}$ stage micrometer.

\section{Results}

\section{Spawning and embryonic developmental stages (Figs 1-6)}

The brood fishes spawned naturally after a maintenance period of 7 months. Six natural spawnings occurred during August to October 2004 with durations ranging from 2 to 4 days for each spawning. The dates of natural spawning invariably corresponded with lunar phase and occurred overnight (Table 1). The number of eggs released in each spawning ranged from 22000 to 180000 and the rate of fertilization and hatching was from 50 to 80 and $60-90 \%$ respectively. The water parameter recorded in the brood stock tank is presented (Table 2).
Table 1 Details on the duration and dates of natural spawning in Epinephelus merra

\begin{tabular}{llrr}
\hline Tank no. & $\begin{array}{l}\text { Spawning } \\
\text { duration (days) }\end{array}$ & Date & \multicolumn{1}{c}{$\begin{array}{l}\text { No. of } \\
\text { eggs }\end{array}$} \\
\hline Tank 1 & 2 & $30-8-04$ & 47800 \\
& & $31-8-04$ & 113600 \\
& 3 & $29-9-04$ & 22000 \\
& & $30-9-04$ & 180000 \\
& 2 & $1-10-04$ & 126000 \\
& & $26-10-04$ & 18000 \\
Tank 2 & 4 & $27-10-04$ & 36500 \\
& & $28-9-04$ & 28000 \\
& & $29-9-04$ & 42700 \\
& & $30-9-04$ & 85000 \\
& 2 & $1-10-04$ & 63200 \\
& & $13-10-04$ & 34500 \\
& 2 & $14-10-04$ & 20000 \\
& & $26-10-04$ & 47000 \\
& & $27-10-04$ & 23500 \\
\hline
\end{tabular}

Table 2 Hydrographical parameters in the indoor maturation and spawning tanks

\begin{tabular}{lllll}
\hline Tank no. & $\begin{array}{l}\text { Temperature } \\
\left({ }^{\circ} \mathbf{C}\right)\end{array}$ & $\mathbf{p H}$ & $\begin{array}{l}\text { Salinity } \\
\text { (ppt) }\end{array}$ & $\begin{array}{l}\mathrm{DO}_{2} \\
(\mathbf{m L L}\end{array}$ \\
\hline 1 & $27.0-28.3$ & $7.97-8.41$ & $32.2-34.1$ & $4.85-5.29$ \\
& $(27.6)$ & $(8.19)$ & $(32.9)$ & $(5.07)$ \\
2 & $27.1-28.3$ & $7.99-8.41$ & $32.3-33.7$ & $4.97-5.36$ \\
& $(27.9)$ & $(8.22)$ & $(32.9)$ & $(5.20)$ \\
3 & $26.5-28.0$ & $8.29-8.61$ & $33.3-34.6$ & $5.05-5.25$ \\
& $(27.0)$ & $(8.27)$ & $(34.1)$ & $(5.15)$ \\
\hline
\end{tabular}

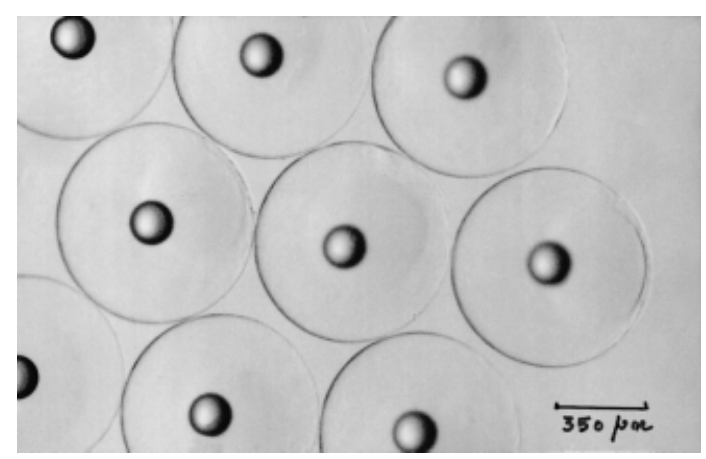

Figure 1 Fertilized eggs.

Eggs were single, perfectly spherical, non-adhesive and buoyant. The size of the eggs measured between 710 and $730 \mu \mathrm{m}$. The fertilized eggs developed the periviteline space immediately following fertilization (Fig. 1). Embryonic cell division started and the eggs reached two, four, eight, 16 and 32-celled stages within 


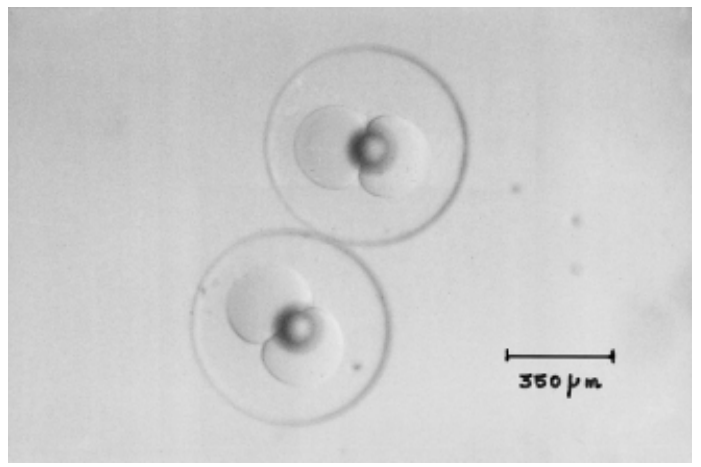

Figure 2 Two-celled stage.



Figure 3 Eight-celled stage.

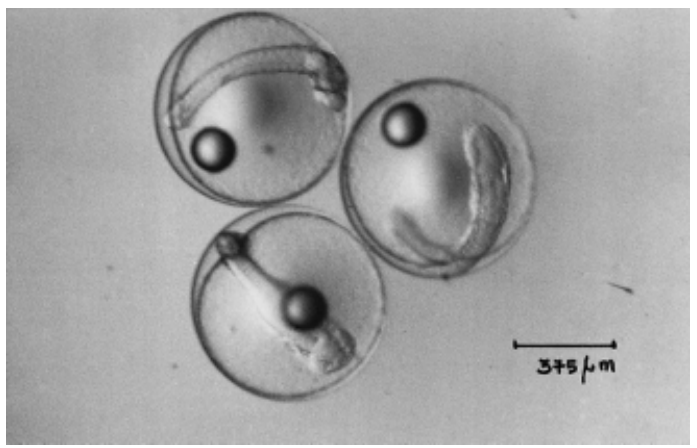

Figure 4 Notochord stage.

$1 \mathrm{~h}$ and $35 \mathrm{~min}$ (Figs 2 and 3). Further cell divisions progressed and by $3 \mathrm{~h}$ and $15 \mathrm{~min}$, reached multicelled stage. Blastula was observed in the fifth hour and gastrula after $7 \mathrm{~h}$ and $30 \mathrm{~min}$. The early embryo stage with fully formed notochord and eye vesicle developed at $11 \mathrm{~h}$ and $30 \mathrm{~min}$ after fertilization, when the egg size was $750 \mu \mathrm{m}$ (Fig. 4). Further embryonic development took place between 14 and $24 \mathrm{~h}$ (Fig. 5). The fertilized eggs hatched within $24-27 \mathrm{~h}$ by breaking the eggshell and wriggling out (Fig. 6).

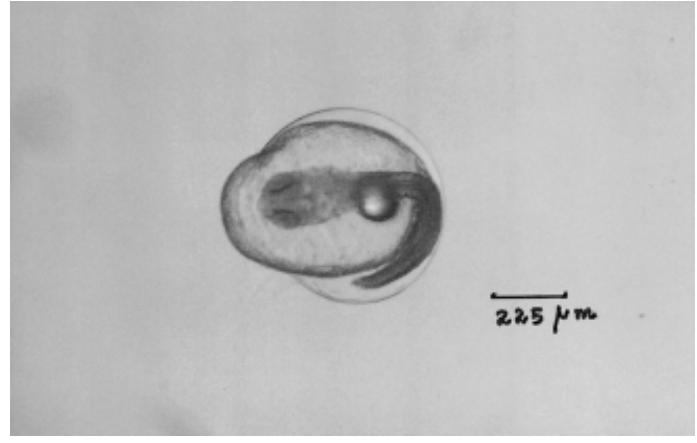

Figure 5 Just before hatching.

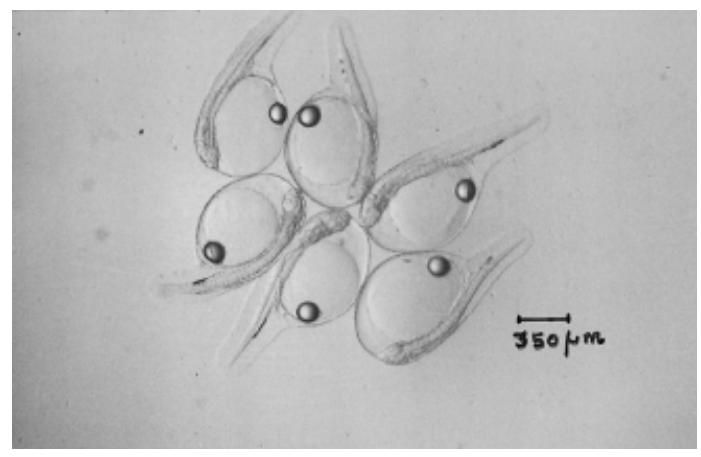

Figure 6 Hatchlings.

Table 3 Hydrographical parameters in the larval rearing tanks

\begin{tabular}{lllll}
\hline $\begin{array}{l}\text { Tank size } \\
(\mathbf{L})\end{array}$ & $\begin{array}{l}\text { Temperature } \\
\left({ }^{\circ} \mathbf{C}\right)\end{array}$ & $\mathbf{p H}$ & $\begin{array}{l}\text { Salinity } \\
\mathbf{( p p t )}\end{array}$ & $\begin{array}{l}\mathbf{D O}_{\mathbf{2}} \\
\left(\mathbf{m L} \mathbf{L}^{-\mathbf{1}}\right)\end{array}$ \\
\hline 250 & $27.5-28.8$ & $7.9-8.4$ & $32.6-34.2$ & $4.9-5.3$ \\
1000 & $28.9-29.5$ & $7.9-8.5$ & $33.5-34.9$ & $4.9-5.2$ \\
5000 & $26.5-28.1$ & $8.3-8.6$ & $33.6-34.6$ & $5.1-5.3$ \\
\hline
\end{tabular}

\section{Larval developmental stages (Figs 7-14)}

Newly hatched larvae were transferred to $100 \mathrm{~L}$ larval rearing tanks and the developmental stages were monitored. The water quality parameters such as temperature, salinity and dissolved oxygen were recorded in the larval rearing tanks (Table 3). The larvae were transparent and floating in the water column after hatching took place. The newly hatched larvae measured between 1.4 and $1.6 \mathrm{~mm}$ (average, $1.5 \mathrm{~mm}$ ) in length and had prominent yolk sac and an oil globule (Fig. 7). Heartbeats were visible in the larvae. The larvae subsequently progressed in length and the yolk sac progressively diminished. The anal tract development was observed by the 28 th hour 


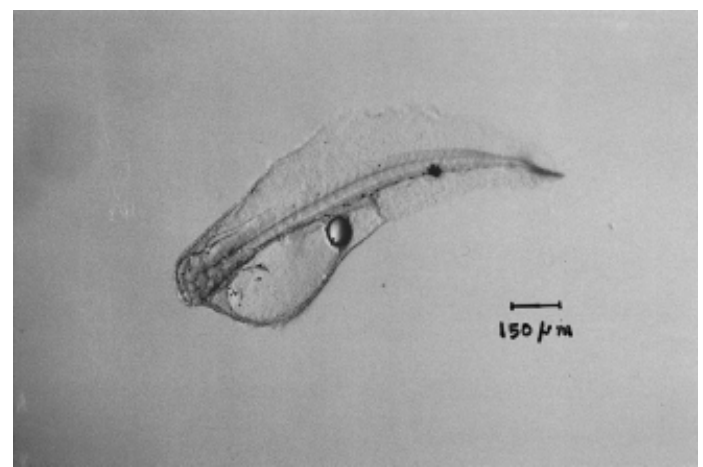

Figure 7 One day old larvae.



Figure 8 Third day-mouth opening stage.

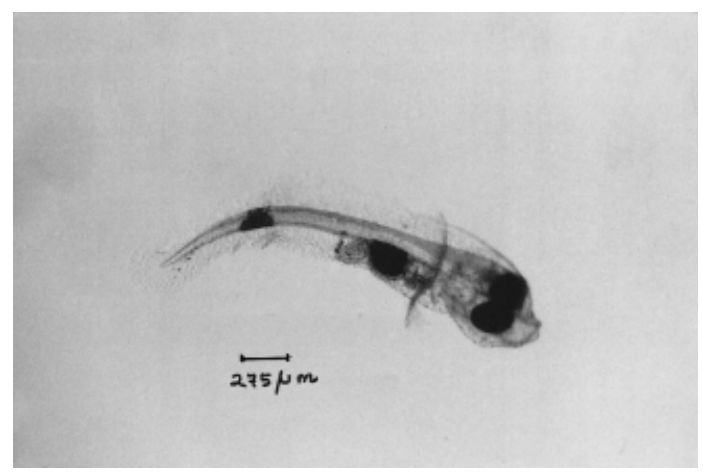

Figure 9 Fifth day larvae.

(1.7 $\mathrm{mm})$. The eyes became very prominent at the 30th hour $(1.8 \mathrm{~mm})$ and at the 36th hour they grew to $1.9 \mathrm{~mm}$ and yolk sac was partly absorbed. At the 48th hour the yolk sac was completely absorbed $(2.0 \mathrm{~mm})$, internal organs such as gut formation were prominent and caudal fin rays had developed.

Mouth cleft appeared at $72 \mathrm{~h}$ (Fig. 8). Complete pigmentation was observed in eye. By 82-92 h, the mouth had fully developed $(115 \mu \mathrm{m})$. Pectoral fin

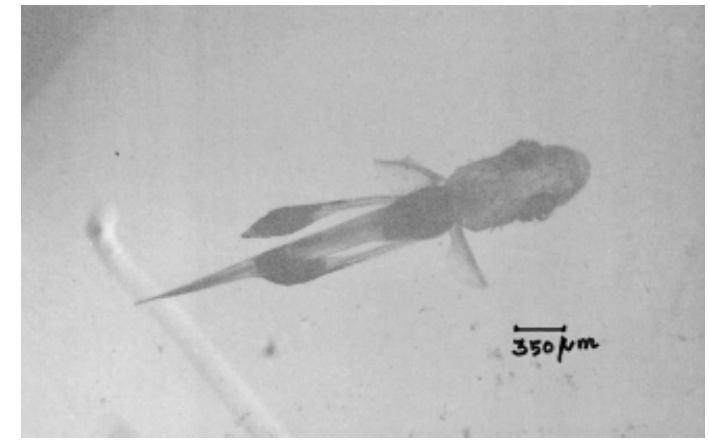

Figure 10 Ninth day larvae.

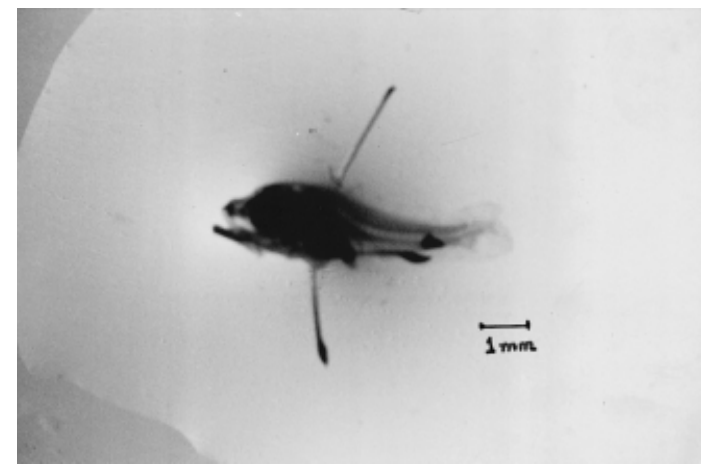

Figure 11 20th day larvae.

development was seen on the fifth day $(2.5 \mathrm{~mm})$ and the larvae started actively swimming (Fig. 9). Subsequently the larvae grew in length and attained $3.2 \mathrm{~mm}$ on the ninth day (Fig. 10), and the larvae developed pigments on the dorsal region and were actively chasing the feed. The larvae attained a length of $3.6 \mathrm{~mm}$ on the 12th day by which time the dorsal and pectoral fins developed. On the 16th $(4.7 \mathrm{~mm})$ day the dorsal, pelvic and pectoral fins become very prominent. By the 20th day the larvae grew to $6.0 \mathrm{~mm}$. Three dorsal spines were very prominent and the second dorsal spine was very long and had serrations on both the sides and the first and third spines without serrations (Fig. 11).

On the 30th day, the larvae had grown to $13.5 \mathrm{~mm}$ and had well-developed teeth in both the jaws. Body muscle bands are also very clear (Fig. 12). The larvae further increased in size and reached $28 \mathrm{~mm}$ on the 48th day to become a fry (Fig. 13). The fry almost resembled adult grouper. The fin spines and rays were very prominent in the dorsal and anal fins. The fry completely transformed into juveniles by developing skin colouration and honeycomb pattern of the adult on the 60th day and measured 45-50 mm (Fig. 14). 


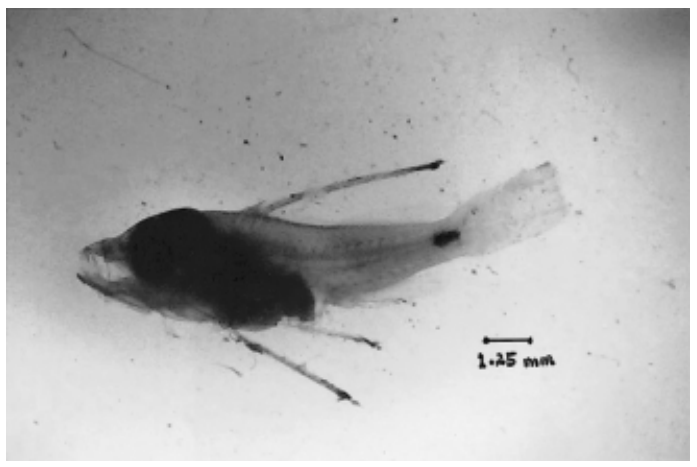

Figure 12 30th day larvae.



Figure 13 48th day (fry).

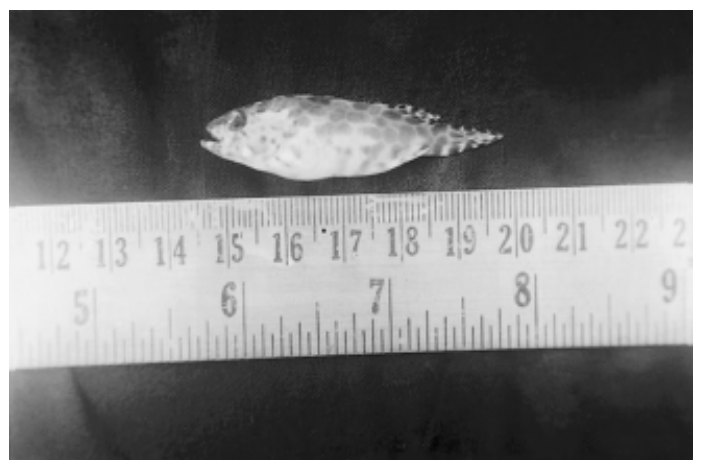

Figure 14 Juvenile (60th day).

\section{Discussion}

Epinephelus merra, stocked in indoor maturation and spawning tanks spawned naturally after a period of about 7 months of maintenance. Similarly, Tucker (1999) stated that natural spawning of captive groupers has occurred mostly with well fed, uncrowded fish during the natural spawning seasons under conditions of ambient temperature and partial or total natural light.
The egg size of E. merra ranged from 710 to $730 \mu \mathrm{m}$ near similar to E. polyphekadion 730-780 $\mu \mathrm{m}$ (Salem \& James 1996) and smaller to the egg size of E. tavina, which is $900 \mu \mathrm{m}$ (Chen et al. 1977; Anon, 1998-1999). The number of eggs released in each spawning and the rate of fertilisation and hatching is comparatively lesser to that of E. polypekadion and E. fuscoguttatus (Salem \& James 1996; Anon, 2000-2001), which may be attributed to the size of the fish.

The duration of early embryonic development of E. merra in the present observation was almost similar to that of E. tauvina, which took about $24 \mathrm{~h}$ for hatching (Chen et al. 1977).

The larvae of most grouper species are small, fragile and had small mouth gape at first feeding stage. Similarly, the larvae of E. merra were also fragile and had small mouth gape. The hatchling size of E. merra was between 1.4 and $1.6 \mathrm{~mm}$ unlike the other species where it was 1.6-2.3 mm (Tucker, 1999). However, it was more similar to that of the hatchling size of E. polyphekadion (Anon, 2000-01). The yolk sac in Nassau grouper eggs tend to reduce quickly after 2-5 days (Tucker, 1999) and in case of E. merra also almost complete absorption of yolk took place by $48 \mathrm{~h}$.

The larval growth of E. merra in length was similar to the growth of E. tauvina observed in Singapore waters up to the 20th day. Subsequently, the growth rate of the larvae was slower and reached a size of $13.5 \mathrm{~mm}$ on the 30th day and $28.0 \mathrm{~mm}$ on the $48 \mathrm{th}$ day when compared with the growth observed for E. tauvina, which is 25 and $70 \mathrm{~mm}$ on the 33rd and 50th day respectively (Chen et al. 1977). The difference in the growth rate and size attained may be attributed to genetic factor, as E. merra is a small sized grouper species compared to E. tauvina.

The percentage of larval survival to the fry stage was less than $1 \%$ as in the case of E. tauvina observed earlier (Chen et al. 1977). Complete transformation of larvae into juveniles takes place between 46 and 70 days in case of Nassau grouper E. striatus (Tucker, 1999), which is comparable with the present species also.

\section{Acknowledgments}

The authors express their sincere thanks to the Director, CMFRI, Kochi for his kind encouraging support and permission to publish this paper. The cooperation and extension of facilities by the Scientist in charge, MRC of CMFRI. Mandapam Camp is thankfully acknowledged. Thanks are also due to Dr K.K. Appukuttan, Head, MFD and Nodal Officer, 
NATP and Head, Mariculture Division for their help in various stages. Our sincere thanks to the Authorities of NATP, New Delhi, for the funds provided for the project.

\section{References}

Anon. (2000-01) Annual Report. Central Marine Fisheries Research Institute, Kochi, India.

Anon. (1998-99) Annual Report, Central Marine Fisheries Research Institute, Kochi, India.

Chen F.Y., Chow M., Chao T.M. \& Lim R. (1977) Artificial spawning and larval rearing of the grouper Epinephelus tauvina (Forskal) in Singapore. Singapore Journal of Primary Industries 5, 1-21.

Duray M.N., Estudillo C.B. \& Alpasan L.G. (1995) Optimum stocking density and tank size for larval rearing of the grouper
(Epinephelus coioides). Paper presented at The Fourth Indian Fisheries Forum, 16-20. October 1995. Beijing, China. Gopinathan C.P. (1982) Methods of culturing phytoplankton. In Manual of Research Methods for Fish and Shellfish Nutrition (Special Publication 8) (ed. by E.G. Silas) pp. 113-118. CMFRI, Cochin, India.

Pinij K.P., Tiro L.B., Pudadera B.P. \& Potestas I.O. (1986) Induced spawning and larval rearing of grouper (Еpinephelus salmoides Maxwell). In The first Asian Fisheries Forum (ed. by J.L. Maclean, L.B. Dizon \& L.V. Hosillos), pp. 663666. Asian Fisheries Society, Manila, Philippines.

Salem A.T. \& James C.M. (1996) Developments in grouper culture in Saudi Arabia. INFOFISH International 1, 22-29.

Stottrup J.F. \& Norsker N.H. (1997) Production and use of copepods in marine fish larviculture. Aquaculture 155, 231247.

Tucker J.W. Jr. (1999) Species profile Grouper Aquaculture. Southern Regional Aquaculture Publication No. 721. 